\title{
Assessment of educational health problems among liver cirrhosis patients to improve their Quality Of Life in Minia University Hospital
}

\author{
Sahar Hamza Taha, Warda Yousef Mohamed, Fatma Al-zahraa Sayed Bukhary, Samia Mahmoud Teleb \& \\ Lobna Mohamed Gamal.
}

Assistant Lecturer of Medical-Surgical Nursing, Faculty of Nursing, Minia University, Egypt .

Prof. of Medical Surgical Nursing, Faculty of Nursing, Cairo University, Egypt .

Prof. of Internal Medicine, Faculty of Medicine, Minia University, Egypt .

Assistant Prof. of Adult Nursing, Faculty of Nursing, Assiut University, Egypt .

Lecturer of Medical-Surgical Nursing, Faculty of Nursing, Minia University, Egypt .

\begin{abstract}
Back ground: Liver cirrhosis is a serious chronic disease, affects most of body systems and reduce patient's quality of life (QOL). It needs a nursing guidelines to be developed according to patient's needs. Aim of this study was to assess educational needs of liver cirrhosis patients, (assessment of QOL domains, liver cirrhosis health problems and complications) to improve their quality of life. Descriptive research design has been used to carry out this study. Patients and methods: The study sample included 50 male and female patients with liver cirrhosis. Setting internal medical department, Minia University Hospital. Structured interview was utilized for data collection. Three tools were utilized for data collection; Tool I-Liver cirrhosis patient's knowledge questionnaire sheet, Tool II- Knowledge assessment questionnaire, Tool III- Chronic Liver Disease Questionnaire. Results: the majority of patients were married, housewives, illiterate, and come from rural areas $(82 \%, 50 \%, 80 \%, 88 \%$ respectively) and their age ranged between 50 and 59 years, patient's QOL domains mean scores were low with worry, activity, fatigue, abdominal and systemic symptoms. The patient's mean knowledge scores about liver cirrhosis, complications, and diet were also low. Conclusion, continuous education of liver cirrhosis patients is needed to prevent complications of cirrhosis and improvement of health related quality of life.
\end{abstract}

Key words: Assessment-Liver Cirrhosis- Quality Of Life \& Chronic Liver Disease Questionnaire.

\section{Introduction}

Cirrhosis is a serious and irreversible disease (Khan \& Zarif , 2006) which affects most of the body organs and systems (Kashifard et al., 2010). Cirrhosis is one the most important causes of death in the world and therefore, is considered as one of the major health issues (Minakari et al., 2011).

Liver cirrhosis is defined in histology as a bridging fibrosis-a late stage of hepatic fibrosis-leading to deranged liver architecture and regenerative nodules. Liver cirrhosis is considered the end stage of a variety of chronic liver diseases, and is irreversible in its advanced stages. Liver cirrhosis carries the risk of life-threatening complications, partly due to a number of co-morbidities. Medical treatments that may halt the progression of compensated cirrhosis to decompensated cirrhosis are currently being developed(Schuppan \& Afdhal, 2008).

(Grattagliano et al., 2011) found that life expectancy and quality of life in patients with advanced cirrhosis remains poor, patients experience fatigue, pruritus, ascites, bleeding and encephalopathy, dyspepsia and malnutrition are common. Targeted therapy is crucial in slowing or even halting disease progression and to provide standard medical care. Attention should be given to active immunization, nutrition, and general healthcare.

During recent years, assessment of health-related quality of life (HR-QOL) of patients with chronic diseases has become a goal (Wan et al., 2011). Researches show that health-related quality of life (HR-QOL) is damaged in patients with cirrhosis (Kalaitzakis et al., 2008). The quality of life of these patients is affected by the complications and limitations

which causes disorder in activities, social functioning and the psychological state of the patient (Burra et al., 2005).

Liver cirrhosis is one of the illnesses that can change many aspects of life of not only the individual but also their family and affects society ( Pashaee et al., 2010). Liver cirrhosis has become a significant health problem for liver cirrhosis patients' care giver. Patients with liver cirrhosis need knowledge counselling and support to enable them to adjust to their chronic illness. Enrichment of patients with knowledge about liver cirrhosis disease and it's management seems to have a positive effects on improvement of physical responses and can lead to 
improvement of clinical outcomes (Weheida et al., 2009).

\section{Significance of the study}

The World Health Organization (2011) Estimated that Egypt comes first world wide in hepatitis C (HCV) prevalence with more than 22 percent suffering from the disease and shocking yearly number of infections exceeding 165.000.

In Minia University Hospital ,it has been found from the hospital records 2008-2009 that about 1179 patients diagnosed with liver cirrhosis were admitted to general medical department. (Fischer, 2004) found that, More than 170 million people world wide are chronically infected with the hepatitis $\mathrm{C}$ virus(HCV). Chronic infection with $\mathrm{HCV}$ may have serious consequences, $15-20 \%$ of those with chronic infection will develop cirrhosis after 20 years and of these, $5-10 \%$ will develop hepatocellular carcinoma. The cost of cirrhosis in terms of human suffering, financial burden, and loss of productive life is devastating (Zandi et al., 2005).

\section{Aim of the study}

The aim of the present study is to assess educational health problem among liver cirrhosis patients, to design an educational program for these patients as indicated by knowledge related to liver cirrhosis, assessment of QOL domains, liver cirrhosis health problems and complications.

\section{Research questions}

To achieve the above aim of this study the following question should be answered:

Q1: Is liver cirrhosis patient's quality of life affected by their educational health problems?

Q2: What are the educational health problems among liver cirrhosis patients at Minia university hospital?

\section{Subjects \& Methods}

\section{Research design}

Descriptive research design has been used to carry out this study.

\section{Sample size}

Convenience sample (50 patients) of those diagnosed with liver cirrhosis in Minia University Hospital. The determination of the sample size is based upon the following sample calculation formula: http://www.ifad.org/gender/tools/hfs/ anthropometry).

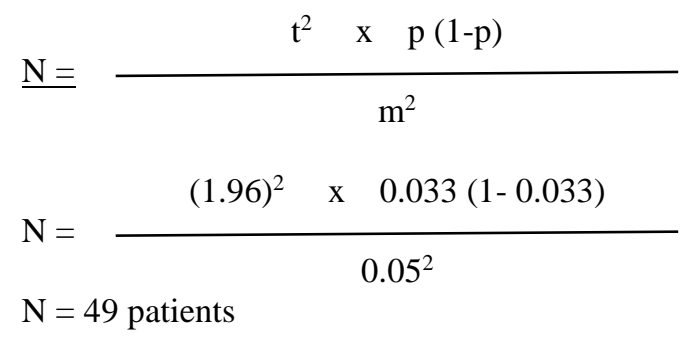

\section{Description}

$\mathrm{N}=$ required sample size

$\mathrm{t}=$ confidence level at $95 \%$ (standard value of 1.960)

$p=$ estimated prevalence of liver cirrhosis in general medical department at Minia University Hospital $2009(0.033)$

$\mathrm{m}=$ margin of error at $5 \%$ (standard value of 0.050 )

Inclusion criteria included patients diagnosed with liver cirrhosis according to child's pugh classification- class B which indicates a moderate hepatic impairment (Child's Pugh classification is a scoring system used to determine the prognosis with cirrhosis. Scoring is based upon several factors: albumin, ascites, total bilirubin, prothrombin time, and encephalopathy), and their age ranged between 20-60 years are legible for the study.

Excluded from the current study patients with diabetes, chronic renal failure, stroke and malignancy.

Setting

The study was conducted at the Internal Medical Department at Minia University Hospital.

Study Tools: To achieve the purpose of the current study the following tools will be used:

Tools will compose of two tools:

Tool one- Liver cirrhosis patient's knowledge questionnaire sheet

This tool was constructed by the researcher based on the current related literature (Zandi et al, 2005) . It consists of 2 parts:

Part I: Socio demographic and medical data of the subjects including patient's age, sex, marital status, place of residence, telephone number, level of education, and occupation, medical diagnosis, child's class of cirrhosis, and laboratory investigations.

Part II: Patient's knowledge assessment to assess patients' knowledge regarding liver cirrhosis, it's common problems such as fatigue, itching, dry mouth, muscular cramps, and its management.

Scoring system

Each right answer was given one score. Those who obtained less than $60 \%$ were considered having unsatisfactory knowledge level, equal or more than $60 \%$ were considered having satisfactory level.

Tool two: Chronic liver disease questionnaire (Younossi et al., 1999): Chronic liver disease 
questionnaire (CLDQ) is used to measure QOL in chronic liver disease patients, include 29 items in the following six domains: abdominal symptoms, fatigue, systemic symptoms, activity, emotional function and worry.

\section{Scoring system}

The scores for each item were summed to create a total score from 25 to 125 , using 5 likert scale (A Likert scale is an ordered scale from which patients choose one option that best aligns with their condition). Type of answers and scores are as the following from worst to best QOL: "all of the time" take 1 score, "most of the time" take 2 score, "a little of the time" take 3 score, "hardly any of the time" take 4 score, and "none of the time" take 5 score.

\section{Operational design}

\section{Methods}

Was concerning formulation of the study tools by the researcher based upon extensive review of related literature, and then the content validity of the tools was checked and revised by 5 nursing and medical experts.

The construct validity of the chronic liver disease question (CLDQ) was supported by a strong correlation with patients' global rating scores ( $\mathrm{r}=$ 0.84; $\mathrm{p}=0.02$ ). Reliability was determined from Cronbach's alpha and test-retest. Cronbach's alpha was higher than 0.91 for domains and it was 0.93 for overall scores.

\section{Tools testing \& pilot study}

A pilot study was implemented on 5 patients to test the clarity of the tools, estimate the time needed for data collection, and test the feasibility of conducting the research, minimal modifications were done and those patients were excluded from the actual study.

\section{Technique for data collection}

A structured interview was utilized to fill out the two tools.

- An official permission to conduct the proposed study was obtained by the researcher from the head of the department, and patient consent to participate in the study after the researcher explained the aim of the study.

- Researcher interviewed patients individually to fulfill socio-demographic and medical data, and knowledge about the disease for all patients.

- At initial interview, the researcher introduce herself to initiate line of communication, explain the nature, purpose of the study, fill out the two tools of the study.

- After that the patient interviewed individually to fulfill socio-demographic and medical data, knowledge test as a base line to assessment.

- The interview was conducted by the researcher in a simple Arabic language.

\section{Ethical and legal considerations}

The patient was informed about the purpose and nature of the study. The researcher emphasized that the participation is voluntary; confidentiality and anonymity of the subjects were assured through coding of all data. Each patient has the right to withdraw from the study at any time without any rational and this data will not be reused without a second permission from them.

\section{Statistical design}

Collect data were verified prior to computerized data entry. Descriptive and inferential statistics were calculated (e.g., frequency, percentage, mean, and standard deviation). Using ANOVA test among quantitative variables. Statistical significance difference was considered when statistical significance was considered at $p$-value $<0.05$.

\section{Results}

The aim of the present study is to assess health problems among liver cirrhosis patients, as indicated, by knowledge related to liver cirrhosis and assessment of health related quality of life domains. Findings of this study are presented in two different parts. The first one focused on the socio-demographic and medical data. The second section provided data about: patient's responses to CLDQ related to abdominal symptoms, fatigue, systemic symptoms, activity, emotional function and worry domains, the compliance of patients to their therapeutic diet, and total and subtotal knowledge scores among sample group. 
The first part

Table (1): Frequency distribution of the study sample in relation to the socio- demographic characteristics.

\begin{tabular}{|c|c|c|}
\hline \multirow{2}{*}{ Variables } & \multicolumn{2}{|c|}{ Study $(n=50)$} \\
\hline & No. & $\%$ \\
\hline \multicolumn{3}{|l|}{ Sex } \\
\hline - $\quad$ Male & 25 & 50.0 \\
\hline - $\quad$ Female & 25 & 50.0 \\
\hline \multicolumn{3}{|l|}{ Age: (years) } \\
\hline - 20-29 years & 1 & 2.0 \\
\hline - $30-39$ years & 4 & 8.0 \\
\hline - $40-49$ years & 10 & 20.0 \\
\hline - $\quad 50-59$ years & 26 & 52.0 \\
\hline - 60 years & 9 & 18.0 \\
\hline Mean \pm SD & \multicolumn{2}{|c|}{$51.6 \pm 7.916$ years } \\
\hline \multicolumn{3}{|l|}{ Marital status } \\
\hline - $\quad$ Married & 41 & 82.0 \\
\hline - $\quad$ Divorced & 1 & 2.0 \\
\hline - $\quad$ Widow & 8 & 16.0 \\
\hline \multicolumn{3}{|l|}{ Residence } \\
\hline - Urban & 6 & 12.0 \\
\hline - $\quad$ Rural & 44 & 88.0 \\
\hline \multicolumn{3}{|l|}{ Occupation } \\
\hline - Housewife & 25 & 50.0 \\
\hline - $\quad$ Laborer & 3 & 6.0 \\
\hline - $\quad$ Government Employees & 3 & 6.0 \\
\hline - $\quad$ Private work & 7 & 14.0 \\
\hline - $\quad$ Not work & 12 & 24.0 \\
\hline \multicolumn{3}{|l|}{ Level of education } \\
\hline - $\quad$ Illiterate & 40 & 80.0 \\
\hline - $\quad$ Read and write & 5 & 10.0 \\
\hline - $\quad$ Secondary education & 2 & 4.0 \\
\hline - University education & 3 & 6.0 \\
\hline
\end{tabular}

The second part

Table (2): Frequency and Percentage Distribution of Patients Responses to CLDQ Related to the Abdominal Symptoms Domain.

\begin{tabular}{|l|c|c|}
\hline \multicolumn{1}{|c|}{ CLDQ } & \multicolumn{2}{c|}{ Sample Group (n= 50) } \\
\cline { 2 - 3 } & No. & \multicolumn{2}{c|}{ \% } \\
\hline 1-Abdominal symptoms (AS) & 6 & 12.0 \\
\hline How much of the time during the last two weeks have you been troubled by a feeling of abdominal bloating? \\
\hline -Most of the time & 22 & 44.0 \\
\hline -A little of the time & 7 & 14.0 \\
\hline -Hardly any of the time & 15 & 30.0 \\
\hline -None of the time & 1 & 2.0 \\
\hline How much of the time during the last two weeks have you experienced abdominal pain? \\
\hline All of the time & 21 & 42.0 \\
\hline Most of the time & 13 & 26.0 \\
\hline A little of the time & 15 & 30.0 \\
\hline None of the time & & \\
\hline
\end{tabular}


Table (3): Frequency and Percentage Distribution of patient's Responses to CLDQ Related to the Fatigue Domain.

\section{CLDQ}

Sample Group $(\mathbf{n}=\mathbf{5 0})$

\section{2- Fatigue ( FA )}

How much of the time have you been tired or fatigued during the last two weeks?

\begin{tabular}{l|c|c|}
\hline All of the time & 12 & 24.0 \\
\hline Most of the time & 21 & 42.0 \\
\hline A little of the time & 16 & 32.0 \\
\hline None of the time & 1 & 2.0 \\
\hline
\end{tabular}

How often during the last two weeks have you felt sleepy during the day?

\begin{tabular}{|l|c|c|}
\hline All of the time & 3 & 6.0 \\
\hline Most of the time & 15 & 30.0 \\
\hline A little of the time & 15 & 30.0 \\
\hline None of the time & 17 & 34.0 \\
\hline
\end{tabular}

How much of the time in the last two weeks have you been bothered by having decreased strength?

\begin{tabular}{|l|c|c|}
\hline All of the time & 11 & 22.0 \\
\hline Most of the time & 27 & 54.0 \\
\hline A little of the time & 10 & 20.0 \\
\hline None of the time & 2 & 4.0 \\
\hline
\end{tabular}

How often during the last two weeks have you felt a decreased level of energy?

\begin{tabular}{|l|c|c|}
\hline All of the time & 7 & 14.0 \\
\hline Most of the time & 25 & 50.0 \\
\hline A little of the time & 16 & 32.0 \\
\hline Hardly any of the time & 0 & 0.0 \\
\hline None of the time & 2 & 4.0 \\
\hline How often during the last two weeks have you felt drowsy & \multicolumn{2}{|l|}{} \\
\hline Most of the time & 14 & 28.0 \\
\hline A little of the time & 29 & 58.0 \\
\hline Hardly any of the time & 2 & 4.0 \\
\hline None of the time & 5 & 10.0 \\
\hline
\end{tabular}

Table (4): Frequency and Percentage Distribution of Patient's Responses to CLDQ Related to the Systemic Symptoms.

\begin{tabular}{|l|c|c|}
\hline \multicolumn{1}{|c|}{ CLDQ } & \multicolumn{2}{c|}{ Sample Group (n= 50) } \\
\cline { 2 - 3 } & No. & \% \\
\hline 3- Systemic Symptoms ( SS ) & \multicolumn{2}{|c|}{} \\
\hline How much of the time during the last two weeks have you experienced bodily pain? \\
\hline Most of the time & 34 & 24.0 \\
\hline A little of the time & 4 & 8.0 \\
\hline None of the time & \multicolumn{2}{|c|}{} \\
\hline $\begin{array}{l}\text { How much of the time during the last two weeks has shortness of breath been a problem for you in your } \\
\text { daily activities? }\end{array}$ & 2 & 4.0 \\
\hline All of the time & 11 & 22.0 \\
\hline Most of the time & 19 & 38.0 \\
\hline A little of the time & 18 & 36.0 \\
\hline None of the time & 6 & 12.0 \\
\hline How often during the last two weeks have you had muscle cramps? & 11 & 22.0 \\
\hline Most of the time & 10 & 20.0 \\
\hline A little of the time & 23 & 46.0 \\
\hline Hardly any of the time & \multicolumn{1}{|c|}{} \\
\hline None of the time & & \\
\hline
\end{tabular}




\begin{tabular}{|c|c|c|}
\hline \multirow{2}{*}{ CLDQ } & \multicolumn{2}{|c|}{ Sample Group $(n=50)$} \\
\hline & No. & $\%$ \\
\hline \multicolumn{3}{|c|}{ How much of the time have you been troubled by itching during the last two weeks? } \\
\hline All of the time & 1 & 2.0 \\
\hline Most of the time & 3 & 6.0 \\
\hline A little of the time & 7 & 14.0 \\
\hline Hardly any of the time & 0 & 0.0 \\
\hline None of the time & 39 & 78.0 \\
\hline \multicolumn{3}{|c|}{ How much of the time during the last two weeks have you had a dry mouth? } \\
\hline All of the time & 9 & 18.0 \\
\hline Most of the time & 22 & 44.0 \\
\hline A little of the time & 7 & 14.0 \\
\hline Hardly any of the time & 1 & 2.0 \\
\hline None of the time & 11 & 22.0 \\
\hline
\end{tabular}

Table (5): Frequency and Percentage Distribution of Patients Responses to CLDQ Related to Activity Domain.

\begin{tabular}{|c|c|c|}
\hline \multirow{2}{*}{ CLDQ } & \multicolumn{2}{|c|}{ Sample Group $(n=50)$} \\
\hline & No. & $\%$ \\
\hline \multicolumn{3}{|l|}{ 4- Activity ( AC ) } \\
\hline \multicolumn{3}{|c|}{ How much of the time during the last two weeks have you not been able to eat as much as you would like? } \\
\hline All of the time & 2 & 4.0 \\
\hline Most of the time & 16 & 32.0 \\
\hline A little of the time & 27 & 54.0 \\
\hline Hardly any of the time & 0 & 0.0 \\
\hline None of the time & 5 & 10.0 \\
\hline \multicolumn{3}{|c|}{ How often during the last two weeks have you had trouble lifting or carrying heavy objects? } \\
\hline All of the time & 21 & 42.0 \\
\hline Most of the time & 21 & 42.0 \\
\hline A little of the time & 6 & 12.0 \\
\hline Hardly any of the time & 0 & 0.0 \\
\hline None of the time & 2 & 4.0 \\
\hline \multicolumn{3}{|c|}{ How much of the time during the last two weeks have you been bothered by a limitation of your diet? } \\
\hline All of the time & 2 & 4.0 \\
\hline Most of the time & 20 & 40.0 \\
\hline A little of the time & 17 & 34.0 \\
\hline None of the time & 11 & 22.0 \\
\hline
\end{tabular}

Table (6): Frequency and Percentage Distribution of Patients Responses to CLDQ Related to Emotional Function and Worry Domain.

\begin{tabular}{|c|c|c|}
\hline \multirow{2}{*}{ CLDQ } & \multicolumn{2}{|c|}{ Sample Group $(\mathrm{n}=\mathbf{5 0})$} \\
\hline & No. & $\%$ \\
\hline \multicolumn{3}{|l|}{ 5- Emotional function } \\
\hline \multicolumn{3}{|c|}{ How often during the last two weeks have you felt anxious? } \\
\hline Most of the time & 22 & 44.0 \\
\hline A little of the time & 23 & 46.0 \\
\hline None of the time & 5 & 10.0 \\
\hline \multicolumn{3}{|c|}{ How much of the time during the last two weeks have you felt unhappy? } \\
\hline Most of the time & 15 & 30.0 \\
\hline A little of the time & 31 & 62.0 \\
\hline Hardly any of the time & 0 & 0.0 \\
\hline None of the time & 4 & 8.0 \\
\hline
\end{tabular}




\begin{tabular}{|c|c|c|}
\hline \multirow{2}{*}{ CLDQ } & \multicolumn{2}{|c|}{ Sample Group $(n=50)$} \\
\hline & No. & $\%$ \\
\hline \multicolumn{3}{|c|}{ How often during the last two weeks have you been irritable? } \\
\hline All of the time & 1 & 2.0 \\
\hline Most of the time & 32 & 64.0 \\
\hline A little of the time & 13 & 26.0 \\
\hline None of the time & 4 & 8.0 \\
\hline \multicolumn{3}{|c|}{ How much of the time during the last two weeks have you had difficulty sleeping at night? } \\
\hline All of the time & 1 & 2.0 \\
\hline Most of the time & 21 & 42.0 \\
\hline A little of the time & 18 & 36.0 \\
\hline None of the time & 10 & 20.0 \\
\hline \multicolumn{3}{|c|}{ How much of the time during the last two weeks have you had mood swings? } \\
\hline Most of the time & 20 & 40.0 \\
\hline A little of the time & 29 & 58.0 \\
\hline Hardly any of the time & 0 & 0.0 \\
\hline None of the time & 1 & 2.0 \\
\hline \multicolumn{3}{|c|}{ How much of the time during the last two weeks have you been unable to fall asleep at night? } \\
\hline All of the time & 1 & 2.0 \\
\hline Most of the time & 10 & 20.0 \\
\hline A little of the time & 18 & 36.0 \\
\hline Hardly any of the time & 0 & 0.0 \\
\hline None of the time & 21 & 42.0 \\
\hline \multicolumn{3}{|c|}{ How much of the time during the last two weeks have you felt depressed? } \\
\hline Most of the time & 12 & 24 \\
\hline A little of the time & 34 & 68 \\
\hline None of the time & 4 & 8 \\
\hline \multicolumn{3}{|l|}{ 6- Worry (WO ) } \\
\hline \multicolumn{3}{|c|}{$\begin{array}{l}\text { How much of the time during the last two weeks have you been worried that your symptoms will } \\
\text { develop into major problems? }\end{array}$} \\
\hline Most of the time & 11 & 22.0 \\
\hline A little of the time & 34 & 68.0 \\
\hline Hardly any of the time & 1 & 2.0 \\
\hline None of the time & 4 & 8.0 \\
\hline \multicolumn{3}{|c|}{$\begin{array}{l}\text { How much of the time during the last two weeks have you been worried about your condition getting } \\
\text { worse? }\end{array}$} \\
\hline Most of the time & 12 & 24.0 \\
\hline A little of the time & 32 & 64.0 \\
\hline Hardly any of the time & 0 & 0.0 \\
\hline None of the time & 6 & 12.0 \\
\hline
\end{tabular}

Table (7): Comparison of Mean Scores of QOL Domains and Total QOL Scores in the sample group.

\begin{tabular}{|c|c|c|}
\hline CLDQ Domains Scores & Min - max & Mean \pm SD \\
\hline Abdominal symptoms & $2-10$ & $6.42 \pm 2.078$ \\
\hline Fatigue & $5-25$ & $12.72 \pm 3.12$ \\
\hline Systemic symptoms & $5-25$ & $17.6 \pm 3.92$ \\
\hline Activity & $3-15$ & $7.58 \pm 2.06$ \\
\hline Emotional & $8-40$ & $24.2 \pm 4.50$ \\
\hline Worry & $2-10$ & $5.96 \pm 1.41$ \\
\hline Total score of QOL & $25-125$ & $74.48 \pm 6.71$ \\
\hline
\end{tabular}


Table (8): frequency distribution of the studied patients in relation to their compliance to their diet.

\begin{tabular}{|c|c|c|}
\hline \multirow{2}{*}{ Variables } & \multicolumn{2}{|c|}{ Studied patients $(n=50)$} \\
\hline & No. & $\%$ \\
\hline \multicolumn{3}{|c|}{ Nutrition \& eating habits } \\
\hline \multicolumn{3}{|c|}{ 1-Do you follow the diet detected for your condition? } \\
\hline - Yes & 34 & 68.0 \\
\hline - $\quad$ Sometimes & 10 & 20.0 \\
\hline - $\quad$ No & 6 & 12.0 \\
\hline \multicolumn{3}{|l|}{ 2- Is the current amount of taken food } \\
\hline - $\quad$ The same amount as before & 20 & 40.0 \\
\hline - $\quad$ Increased amount & 0 & 0.0 \\
\hline - $\quad$ Decreased amount & 30 & 60.0 \\
\hline \multicolumn{3}{|l|}{ 3-Are your meals contain fried food? } \\
\hline - $\mathrm{No}$ & 21 & 42.0 \\
\hline - Usually & 29 & 58.0 \\
\hline \multicolumn{3}{|l|}{ 4-Are your meals contain stewed food? } \\
\hline - $\mathrm{No}$ & 29 & 58.0 \\
\hline - Usually & 21 & 42.0 \\
\hline \multicolumn{3}{|l|}{ 5- Are your meals contain milk products? } \\
\hline - No & 17 & 34.0 \\
\hline - Usually & 33 & 66.0 \\
\hline \multicolumn{3}{|c|}{ 6- Are the foods you eat containing a large amount of salt? } \\
\hline - No & 40 & 80.0 \\
\hline - Usually & 10 & 20.0 \\
\hline \multicolumn{3}{|l|}{ 7-Are your meals contain vegetables? } \\
\hline - $\mathrm{No}$ & 8 & 16.0 \\
\hline - Usually & 42 & 84.0 \\
\hline \multicolumn{3}{|l|}{ 8-Are your meals contain pickles or spicy? } \\
\hline - $\mathrm{No}$ & 42 & 84.0 \\
\hline - $\quad$ Usually & 8 & 16.0 \\
\hline
\end{tabular}

Table (9): One-way ANOVA test for the mean of total and subtotal knowledge scores among sample group.

\begin{tabular}{|l|c|}
\hline \multicolumn{1}{|c|}{ Group } & Mean \pm SD \\
\hline Knowledge about the disease & $33.16 \pm 4.597$ \\
\hline Knowledge about Liver cirrhosis complications \& Health problems & $19.65 \pm 26.27$ \\
\hline Knowledge about Nutrition and eating habits & $47.54 \pm 3.66$ \\
\hline Knowledge about exercise & $3.62 \pm 0.680$ \\
\hline Total knowledge score & $105.97 \pm 35.21$ \\
\hline
\end{tabular}

Table (1): show that; the majority of studied patients were married, housewives, illiterate, and come from rural areas $(82 \%, 50 \%, 80 \%, 88 \%$ respectively) and their age ranged between 50 and 59 years, with Mean \pm SD 51.6 7.916 .

Table (2): show that, the majority of group patients were troubled by a feeling of abdominal bloating, a little of the time with percentage 44 , and experienced abdominal pain with $42 \%$.

Table (3): show that, the majority of group patients were tired or fatigued, bothered by having decreased strength, and felt a decreased level of energy most of the time with percentage $62 \%, 54 \%, 50 \%$ respectively.

Table (4): shows that, the majority of group patients were complaining from dry mouth most of the time with percentage $44 \%$.

Table (5): shows that the majority of group patients had trouble lifting or carrying heavy objects all and most of the time with percentage $42 \%$ and had been bothered by a limitation of their diet most of the time with percentage $40 \%$. 
Table (6): shows that the majority of group patients were irritable and had difficulty of sleeping at night most of the time with $64 \%, 42 \%$ respectively, with statistically significant differences.

Table (7): show that, the highest mean score of QOL domains was emotional domain with mean $24.2 \pm 4.50$, compared to low mean score of worry domain with mean $5.96 \pm 1.41$.

Table (8): shows that the majority of group patients responded that they follow the diet detected for their

condition, decreased amount of taken food, usually take meals contain fried food, not take meals contain stewed food, usually take meals contain milk

products, didn't eat foods containing a large amount of salt, usually their meals contain vegetables and not contain pickles or spicy with $68 \%, 60 \%, 58 \%$, $58 \%, 66 \%, 80 \%, 42 \%, 84 \%$ respectively.

Table (9): show that, the highest mean knowledge score was about nutrition and eating habits with mean $47.54 \pm 3.66$ compared to low mean Knowledge about exercise with mean $3.62 \pm 0.680$.

\section{Discussion}

The aim of the present study is to assess liver cirrhosis patient's educational needs, as indicated by knowledge related to liver cirrhosis, health problems relieve, prevention of complications and improving quality of life.

The result of the present study, as regards the domain of abdominal symptoms, the majority of the patients in the study sample felt abdominal bloating a little of time, pain and discomfort most of time during the last two weeks in the time of data collection. Also (Furate et al., 2013) found that, In relation to the domain of abdominal symptoms, the majority of the patients in the study sample felt abdominal distension, pain and discomfort most of time during the last two weeks in the time of data collection, more than one third of them felt abdominal pain and discomfort all time, while the minority of them felt it little of time.

These findings are supported by (Garcia \& Lim, 2009) who showed that, symptoms of cirrhosis may develop gradually, when symptoms do occurs they can include abdominal bloating, abdominal indigestion or pain, nausea and vomiting, swelling or fluid build up of the legs, and in the abdomen (ascites), vomiting blood, or blood in stool, weakness and weight loss.

In the present study, the majority of study patients felt tired or fatigued most of time, felt bothered by having decreased strength most of the time, had low energy most of time, and felt drowsy a little of time. This coincides with (Mahmoud et al, 2013) who found that, the majority of patients felt tired all time, felt weakness most of time, and felt low energy most of time.

Recent literatures by (Raefa, 2015) found that, the most common symptoms of chronic liver disease e.g. fatigue, abdominal pain, GI abnormalities exacerbate the quality of life of patient. The nurse and physician can help the patient by counselling them to improve their quality of life.

(Dienstag \& Isselbacher, 2005), asserted that the patient with cirrhosis often experiences severe fatigue, leading to activity intolerance related to bed rest, fatigue, lack of energy and altered respiratory function secondary to ascites.

The results of the present study showed that, the majority of study patients were felt shortness of breathing a little of time, and mouth dryness most of the time. This result goes in agreement with (Chung \& Podolsky, 2005) who stated that ascites leads to many other problems as shortness of breathing related to increased intra- abdominal pressure. In patients with ascites; severe edema as well as other problems may develop problems such as impaired skin integrity, abdominal pain, pruritus (itching). Restriction of fluid also causes mouth dryness and muscle contraction due to electrolyte imbalance.

The current study revealed that, majority of the study sample had trouble lifting or carrying heavy objects all of time, while more than half of them were unable to eat as much as they like and also were bothered to limitation of their meal most of time in the last two weeks of data collection time. As reported by (Blei, 2007), patients with cirrhosis had imbalanced nutrition related to impaired utilization and storage of nutrients, increased pressure on stomach and intestines, feeling full, anorexia, nausea, loss of nutrients from vomiting. They also had activity intolerance related to anemia from poor nutrition and bleeding, ascites, dyspnea from pressure of ascites on diaphragm and muscle wasting, (Abraides \& Bosch, 2007).

(Nairs, 2010), mentioned that when patient bears down and does valsalva manoeuvre to pick up something heavy, he/she can dramatically increase the pressure in esophageal varices, can suddenly bleed. So the patients with esophageal varices should be advised to limit the weight that they left to 40 pounds (18 kilograms).

The current study found that, the majority of the study sample felt irritable most of the time, felt anxious, unhappy, and had insomnia a little of time. As regards to mood swings and feeling depressed, about more than half of them felt it. These results are supported by (Sheikh et al, 2004) who asserted that, the neurologic changes occur with gastrointestinal bleeding, hepatic encephalopathy, and accumulation 
of ammonia impairs memory, attention, concentration and rate of response. Sleep pattern reversal often occurs, with the client awake at night and sleepy during the day.

(JING, 2005) Found that, various factors can result in the occurrence of anxiety and depression in patients with severe cirrhotic ascites. Health education could effectively alleviate the negative spirits of the patients and improve their quality of life.

The current study found that, study sample had high mean scores of CLDQ domains for emotional domain, which means the best QOL and lower mean scores of worry domain, which considered more worst QOL. These findings may resulting from faith of patient's on god as this disease is a test from god to them and they are satisfied with that.

This often not in line with (Gao, 2012) who found that, with the progressing of liver dysfunction, patients with CLD suffer from fatigue, loss of selfesteem, inability to function at work, anxiety, depression, and other emotional problems that profoundly decrease their quality of life and wellbeing.

As regard to patient's mean score for total quality of life, it was low and considered that patients have worse quality of life. This coincides with (Bianchi et al., 2003), (Cordoba, 2005), they stated that chronic liver disease (CLD) had negative effect on QOL and QOL worsened as the severity of disease increased.

Our study findings were agree with (Youssef et al., 2015) who found that, patients had low HRQOL, these findings highlight the needs of patients with liver cirrhosis in Egypt. Engaging the patients' family in care planning may decrease patients' burden and improve their HRQOL. This study also provides a rationale to develop future research in symptom management to enhance HRQOL.

The present study shows that more than half of the subjects were taking a decreased amount of food in their meals than they must take, because they don't know what's avoided and permitted foods, so they avoid many types of foods.

The current study revealed a great lack of patient's knowledge as regard to liver cirrhosis in study sample. The majority of patients, were having an unsatisfactory knowledge score levels. This finding could be attributed to lack of patients education about liver cirrhosis and the majority of those patients were illiterate. (Canobbio, 2000) emphasized that patients with liver cirrhosis need education, counselling and support to enable them to adjust to their chronic illness.

This result also, was in line with (Mohamed, 2005) who recorded that cirrhotic patients with ascites had great learning needs due to the poor knowledge about their condition and a low level of performing self care and prevention of life threatening hazards of liver cirrhosis.

From findings of the present study it was found that, patient and patient's family need health teaching about liver cirrhosis (disease nature, health problems and complications, how to deal with these problems and how to prevent complications, treatment effects and side effects, therapeutic diet), to improve their quality of life. (Joyce and Jane, 2009) support this as he reported that, education is the key to successful treatment of the disease, and the nurse plays a major role as patient educator. Patients and their families need accurate information about the disease and about the strategies to minimize its impact.

These findings supported by (Kocaman et al.,2007), who stated that, Patient and family teaching is an important nursing role that may make the difference in the ability of the patient and family to adapt to chronic conditions. Well-informed, educated patients are more likely than uninformed patients to be concerned about their health and to do what is necessary to maintain it. They are also more likely to manage symptoms, recognize the onset of complications and seek health care early. Knowledge is the key to making informed choices and decisions during all phases of the chronic illness trajectory

(Adibi et al ,2008) also mentioned that is, no doubt, gaining information on this topic is important to look at the topic in detail and from all aspects and to look at cirrhosis from the view point of the patients and their family. Therefore, this research was undertaken with the goal of assessing utility of cirrhosis from the point of view of the patients, their family, and their caretakers to help planners and health service providers for appropriate interventions, training and counseling programs to support patients. Moreover, the identification of affective factors on this illness can encourage caretakers to effectively support these patients.

\section{Study Limitations}

Our assessment was limited by the relatively small number of adult patients. Study of larger populations is desirable to determine the level of knowledge among selective population precisely. Suitable place for data collection was not available in any of the patients.

\section{Conclusions}

Based on results of the present study; the researcher can conclude the following:

- Patient's knowledge regarding liver cirrhosis and its management was unsatisfactory.

- Education of liver cirrhosis patient is necessary to achieve a satisfactory level. 
- Patients with liver cirrhosis had deteriorated quality of life as measured by CLDQ, abdominal symptoms, fatigue, dry mouth, activity, and emotional irritability were major problems and symptoms of cirrhotic patients that impaired the quality of life of those patients.

\section{Recommendations}

Based on results of the present study, the following can be recommended:

- A continuous educational programs to improve patients awareness about liver cirrhosis, it's prevention, and early detection especially high risk patients.

- Written, simple booklet about liver cirrhosis and its management should be provided \& available for patients

- $\quad$ Education of nurses to prevent HCV infection in health care settings.

- Continuous education and follow up in chronic hepatitis $\mathrm{B} \& \mathrm{C}$ patients to decrease it's complications.

- Replication of the study on a large sample and in different hospital settings is recommended for generalization of results.

\section{For further study and research}

- It is recommended that similar studies should be replicated on longitudinal bases to be conducted to assess the compliance and deterioration for such group of patients.

\section{References}

1. Abraides J., Bosch J., The treatment of acute variceal bleeding. Journal (2007): of clinical Gastroenterology,41 (suppl 3), S312-S317.

2. Adibi P., Akbari L., Kahangi L., \& Abdi F., (2008): Health-state utilities in liver cirrhosis International Journal of Preventive Medicine, Special Issue,S101and the health utility index. Liver Transpl, 14(3): 321-6.

3. Bianchi G., Loguercio C., Sgarbi D., Abbiati R., Brunetti N., De simone T., Zoli M., Marchesini G., (2003): Reducing quality of life of patients with hepato cellular carcinoma. Dig. liver. Dis, 35:46-54.

4. Blei A., (2007): Portal Hypertension \& its complications. Current Opinion in Gastroenterology; 23(3),275-282.

5. Burra P., De B ., Canova D., Feltrin A., Ponton A., Ermani M., Burra P., (2005): Longitudinal prospective study on quality of life and psychological distress before and one year after liver transplantation. Acta Gastroenterol Belg; 68(1): 19-25.
6. Canobbio M., Mosby's H., \& (2000): Book of patient teaching. 2nd ed. Louis, Horcourt health science company; 270-73, 306-10.

7. Chung R., Podolsky D., Cirrhosis \& its' complications in D., Kasper, et al., (2005): (Eds), Harrison's principles of interol medicine $\left(16^{\text {th }}\right.$ ed) New york: MC Graw-Hill; pp 18581869.

8. Cordoba J., Flavia M., Jacas C., Sauleda S., Esteban J., Vargas V., Estaban R., Guardia J., (2005): Quality of life and congestive function in hepatitis $\mathrm{C}$ at different stages of liver disease J.Hepatol,39:231-238.

9. Dienstag J., Isselbacher K., Acute viral hepatitis. In D.Kasper, et al., (2005): (Eds) Harrison's principles of internal medicine (16th ed) New York: MC Graw-Hill; pp 1858-1869.

10. Fischer B., Injection drug use \& the Hepatitis C., (2004): virus consideration for a target treatment approach to case study of Canada J.urban health;81:428-47.

11. Furat H., \& Mahmoud, Nawal Ebeid, \& Mohamed S., Elaziz. (2013):The Impact of Self-Care Instructional program on Quality of Life of Patients with Liver cirrhosis at El-Kasr EL Ainy Cairo University Hospital. Nature and Science;11(6)

12. Gao R., Gao F., Li G., Hao J., (2012): HealthRelated Quality of Life in Chinese Patients with Chronic Liver Disease, Gastroenterol Res Pract; 516140.

13. Garcia T., Lim J., (2009): Management \& Treatment of Patients With Cirrhosis and Portal Hypertension, American Journal of Gastroenterology; 104:1802-1829.

14. Grattagliano I., Ubaldi E., Bonfrate L., \& Portincasa P., (2011): Management of liver cirrhosis between primary care \& specialists , World J Gastroenterol. May 14; 17(18): 22732282.

15. Jing L., (2005): Effect of Healthy Education on Anxiety, Depression and Quality of Life of the Patients with Severe Cirrhotic Ascites, Journal of Nursing Science ; Issue 1, Page.52-54

16. Kalaitzakis E., Josefsson A., Bjornsson E., (2008): Type and etiology of liver cirrhosis are not related to the presence of hepatic encephalopathy or health-related quality of life: a cross-sectional study. BMC Gastroenterol; 8: 46.

17. Kashifard M., Saravi M., Taheri H., \& Bahreini R., (2010): Echocardiographic findings in cirrhotic patients with and without ascites compared to normal. Journal of Babol University of Medical Sciences; 12(4):48-53.

18. Khan H., \& Zarif M., (2006): Risk factors, complications and prognosis of cirrhosis in a 
tertiary care hospital of Peshawar. Hepatitis Monthly; 6(1): 7-10.

19. Kocaman N., Kutlu Y., \& Ozkan M., (2007): Predictors of psychosocial and adjustment in people with physical disease .Journal of nursing and health care of chronic illness in association with Journal of Clinical Nursing,16(3a),6-16.

20. Mahmoud F., Ebeid N., \& Elaziz M., (2013): The Impact of Self-Care Instructional program on Quality of Life of Patients with Liver cirrhosis at El-Kasr EL Ainy Cairo University Hospital. Nat Sci;11(6):95-105.

21. Minakari M., Faiiaz L., Rowshandel M., \& Shavakhi A., (2011): Comparison of the effect of midodrine versus octreotide on hemodynamic status in cirrhotic patients with ascites. J Res Med Sci ; 16(1): 87-93.

22. Mohamed A., (2005): Impact of pat hart net breathing rehabilitation program on physical responses among patients with ascites, unpublished master degree. Faculty of nursing, Cairo university.

23. Nairs S., \& vitamin D., (2010): deficiency of liver disease, Gastroenterology and hepatology; vol .6.no 8,pp. 491-493.

24. Pashaee F., Taleghani F., Tavakol K., Rezae A., (2010): Family experiences from care giving of patient with coronary artery bypass graft surgery: a qualitative study. IJNR; 5(16): 61-71.

25. Raefa R., (2015): Quality of life of geriatric patients with chronic liver disease. 4th International Conference on Nursing \& Health care, October 05-07 San Francisco, USA

26. Schuppan D., \& Afdhal N., (2008): Liver cirrhosis. Lancet;371:838-851.

27. Sheikh A., \& Fallon M., (2004): Acute \& Chronic Hepatitis. In T.E. Andreali. et al(EDs), Cecil essentials of medicine (6th ed).Philadelphia: saunders; pp 399-407.

28. Wan L., Lee T., Chien C., Chao P., Tsai W., \& Fang F., (2011): Health-related quality of life in 640 head and neck cancer survivors after radiotherapy using EORTC QLQ-C30 and QLQH\&N35 questionnaires. BMC Cancer; 11: 128.

29. Weheida S., Mohsen M., Bahenasy A., Shehata A., \& Heneedy W., (2009): Effect of protocol of care on clinical outcomes of patients with liver cirrhosis, Bull. Alex. Fac. Med; 45 No. 3.

30. Younossi Z., Guyatt G., Kiwi M., Boparai N., \& King D., (1999): Development of a disease specific questionnaire to measure health related quality of life in patients with chronic liver disease. Gut;45:295-300.

31. Youssef N., Shepherd A., \& Evans J,. (2015): Factors associated with health-related quality of life among patients with liver cirrhosis in Egypt. J Egypt Public Health Assoc. Mar;90(1):14-9.

32. Zandi M., Adib-Hajbagheri M., Memarian R., Nejhad A., Alavian S., (2005): Effects of a selfcare program on quality of life of cirrhotic patients referring to Tehran Hepatitis Centre Health and Quality of Life Outcomes; 3:35. 